\title{
Evasion of Newborn Hearing Screening retest: relation with risk factors for hearing impairment
}

\author{
Júlia Dalcin Pinto \\ https://orcid.org/0000-0001-9799-3229 \\ Laís Ferreira \\ https://orcid.org/0000-0002-3244-025X \\ Déborah Aurélio Temp \\ https://orcid.org/0000-0001-6320-6602 \\ Valdani Dias \\ https://orcid.org/0000-0001-5868-233X \\ Dara Eliza Rohers \\ https://orcid.org/0000-0003-4198-3835
}

Eliara Pinto Vieira Biaggio

https://orcid.org/0000-0003-2989-5787

Universidade Federal de Santa Maria, Departamento de Fonoaudiologia, Santa Maria, Rio Grande do Sul, Brasil.

Conflict of interests: Nonexistent

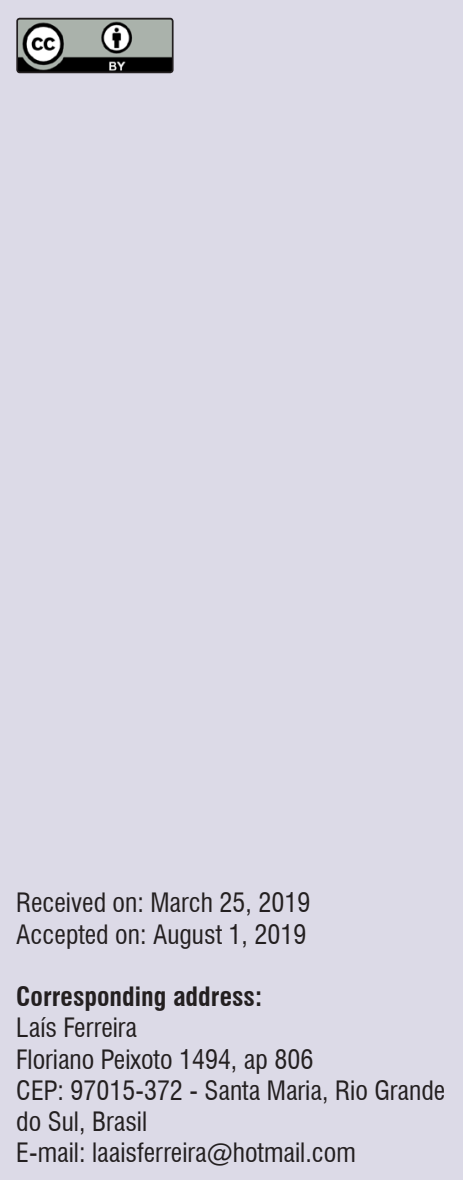

\section{ABSTRACT}

Purpose: to analyze the evasion rate of the Newborn Hearing Screening program's retest, to verify whether the presence of risk indicators for hearing loss influences it, and to describe which risk indicators for hearing loss occur more frequently in these cases.

Methods: 1,287 newborns/infants participated, who were screened between June 2015 and June 2018. All of them obtained "fail" as the Newborn Hearing Screening result, were referred to the retest and did not attend it. Information related to the occurrence of risk indicators for hearing loss was observed.

Results: the study found that the evasion rate was of $15.23 \%$. The presence of risk indicators for hearing loss did not show an association with non-attendance at this stage of the program ( $p$-value $=0.087$ ). The most frequent indicators in the cases of non-attendance at the retest were: ototoxic medication use and intensive care unit stay for more than five days.

Conclusion: high evasion rate of the retest has been observed. It has been found that the presence of risk indicators did not influence the retest evasion rate. Use of ototoxic medication and stay at the intensive care unit were the most frequent indicators among those who did not attend the retest.

Keywords: Newborn Screening; Newborn; Hearing; Risk Indicator 


\section{INTRODUCTION}

In the first years of life, hearing is essential for the typical development of oral language acquisition. Being deprived of hearing in this period impairs not only the communicative development but also the child's global development, causing loss in their social, cultural and intellectual contexts ${ }^{1,2}$.

Hearing Loss $(\mathrm{HL})$ is the most frequent sensorial deficit occurring in human beings ${ }^{3}$. According to data from the World Health Organization (WHO), 466 million people suffer from some degree of $\mathrm{HL}, 34$ million of which are children4.

Despite advances in technology and diagnosis techniques, the incidence of people presenting such disorders is increasing, and tends to keep growing in the next decades, as the current figures of people with hearing loss are foreseen to double by $2050^{4}$. However, WHO estimates that $60 \%$ of these cases in children may be avoided by means of preventive measures and public health strategies ${ }^{5}$.

The Newborn Hearing Screening (NHS) is the gold standard strategy, the most effective means of detecting newborns and infants suspected to have $\mathrm{HL}$ in their early childhood ${ }^{6}$. This program is part of the Brazilian National Auditory Healthcare Policy, established by Regulation GM/MS no. 2,073 of 2004. Conducting the screening is the first step in an auditory health program and must be preferably carried out before hospital discharge, with the intention of enabling early diagnosis and intervention, since these factors are crucial for the success in auditory and language development in children with $\mathrm{HL}^{7}$. In Brazil, it's been obligatory since 2010, as enforced by the Federal Law 12,303/10.

It should be highlighted that the occurrence of $\mathrm{HL}$ is up to 10 times higher in high-risk newborns ${ }^{8}$. In literature ${ }^{9}, 10$ factors characterized as risk indicators of hearing loss (RIHL) are described, namely: parents' concern regarding their children's development, auditory, speech or language development, history of deafness in the family, ICU stay for more than five days, ototoxic medication use, mechanical ventilation, hyperbilirubinemia with exchange transfusion, low Apgar score in the first minutes of life ( 0 to 4 in the first minute, or 0 to 6 in the fifth minute), weight at birth below 1,500 grams, and prematurity. Besides these, congenital infections, craniofacial anomalies, HL-associated genetic syndromes, neurodegenerative disorders, bacterial or viral infections, head injury, and chemotherapy are also considered RIHL. These complications are taken into account when choosing the most adequate NHS protocol for each case.

As for the NHS result, it's considered positive when the newborn presents an unsatisfactory result, i.e., "fail" in screening, and is suspected to have $\mathrm{HL}$; and negative, in those who show "pass" result in the test, being discharged concerning their hearing. In cases whose NHS results in "fail", it's necessary to perform the retest, which should take place in up to 30 days after hospital discharge ${ }^{9,10}$.

Among the quality indicators of an NHS program, are included the rates of adherence and evasion of the retest, which must be conducted in at least $90 \%$ of newborns that have obtained inconsistent results in screening ${ }^{10}$. However, this figure is far from being reached in Brazilian reality. National studies show the low rate of attendance at retest - data that mars the effectiveness of the program, since the low commitment of parents to concluding the diagnosis negatively impacts the continuity of the program's stages ${ }^{11-13}$.

Currently, the high rate of retest evasion is considered to be one of the greatest challenges for detection and intervention to happen at the appropriate time, which would make possible the good prognosis for the communicative and educational development of the newborn and/or infant. An internationally conducted research concluded that this rate is higher in underdeveloped countries, in which effective measures for the public health development are still precarious ${ }^{14}$.

Having this context in view, the purpose of this study was to analyze the rate of evasion of the Newborn Hearing Screening program retest, and whether the presence of risk indicators of hearing loss influences it, in addition to describing which RIHL are more frequent in these cases.

\section{METHODS}

This study was designed as a quantitative descriptive cross-sectional study, carried out in a public maternity of a university hospital, from June 2015 to June 2018. It was approved by the Research Ethics Committee of the Federal University of Santa Maria under the approval number $2,538,043$. All of those responsible for the newborns agreed to participate in the study, thus signing the informed consent form (ICF), in compliance with the National Health Council's Resolution 466/2012.

Included in the study were newborns and infants (up to three months of age) who had NHS performed and obtained "fail" result, but who did not attend retest. 
Throughout the time of the study, 7,626 newborns and infants were screened in the Newborn Hearing Screening Program of the abovementioned institution; of these, 1,287 became the subjects of this study, having failed the NHS and being referred to the retest stage. In the medical records of the sample group, information related to the presence of RIHL was observed.

The NHS program of the hospital in question benefits newborns still in the maternity, before hospital discharge, and in their Audiology clinic. For better examining conditions, the newborn was in natural sleep, on its mother arms or in the cradle. Following international ${ }^{10}$ and national ${ }^{1}$ guidelines, all newborns not presenting RIHL were screened with the TOAE procedures, while those presenting some indicator were submitted to AABR. Both procedures made use of the Otometrics Accuscreen equipment, which presents an automatic response criterion. The NHS response was considered "pass" in the presence of TOAE and/ or AABR, and "fail" when there was no response. Thus, the newborns who obtained "fail" in the screening were referred to retest, to be performed within 15 days. The retest protocol used in this program consisted of performing the AABR by means of the abovementioned equipment. In such cases, the person responsible for the newborn had previously signed a Statement of Responsibility developed by the NHS program, through which they are committed to, and made responsible for, returning for the retest. The strategy of signing such statement was an alternative found by the service in question to decrease evasion rate of the NHS retes $\mathrm{t}^{15}$.

The data inserted in an electronic spreadsheet were: evasion rate in the retest stage, i.e., the non-attendance at retest after failing in the NHS; and the occurrence of different RIHL of newborns and/or infants that did not attend such stage of audiological diagnosis foreseen in the auditory health program. These data were submitted to statistical analysis by means of Pearson's chi-squared test, besides the descriptive analysis of the results.

\section{RESULTS}

Of the total sample of 7,627 newborns screened during the evaluation period at the hospital in question, $16 \%(n=1,287)$ needed reassessment, and were thus referred to retest. The evasion rate of the NHS retest was of $15.2 \%$ of the sample, i.e., 196 newborns did not adhere to continuing the stages of the program, not attending the retest.

In Figure 1, there can be seen the flowchart with the sampling of newborns screened by the NHS program between the years of 2015 and 2018.

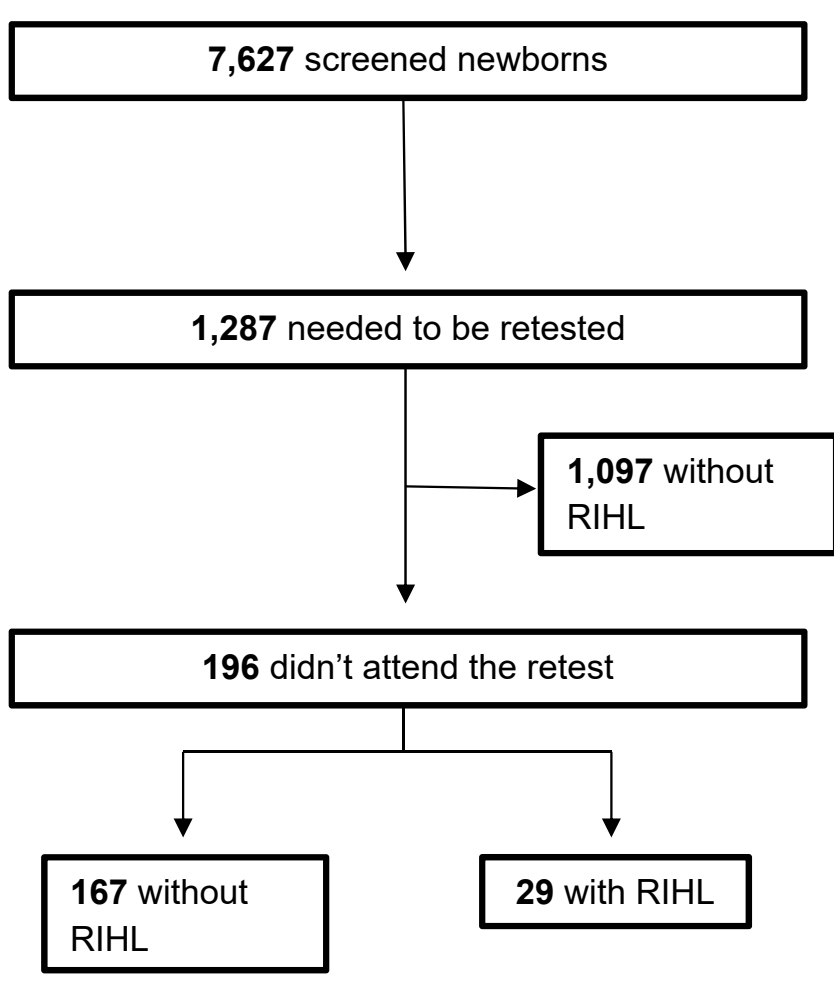

Key: RIHL: Risk Indicator for Hearing Loss

Figure 1. Flowchart with the sample of newborns screened by the Newborn Hearing Screening program: need of retest, evasion of retest, and occurrence of risk indicators

In the sequence, it was analyzed whether the presence of risk indicators for hearing loss had influenced the attendance for performing the retest, by means of the Pearson's chi-squared test, in newborns/ infants of a public NHS program (Table 1). Based on this analysis, it was found that there had been no significant influence of the variable presence of RIHL regarding the adherence to this program's retest stage.

Figure 2 presents the different RIHL found in the newborns/infants that didn't attend the NHS retest. The most frequently registered indicator was that of ototoxic medication, followed by stay in intensive care unit (ICU) for more than five days. It should be highlighted that the $\mathrm{RIHL}$ could have been associated. 
Table 1. Attendance for performing Newborn Hearing Screening retest: relation to the occurrence of risk indicators ( $n=1,287$ newborns/ infants)

\begin{tabular}{cccc}
\hline & Presence at retest & Absence at retest & P-value \\
\hline With RIHL & $161(84.7 \%)$ & $29(15.3 \%)$ & \multirow{2}{*}{0.8} \\
Without RIHL & $930(84.8 \%)$ & $167(15.2 \%)$ & \\
\hline
\end{tabular}

Key: RIHL: risk indicators for hearing loss; \%: percentage

Statistical Test: Pearson's chi-squared

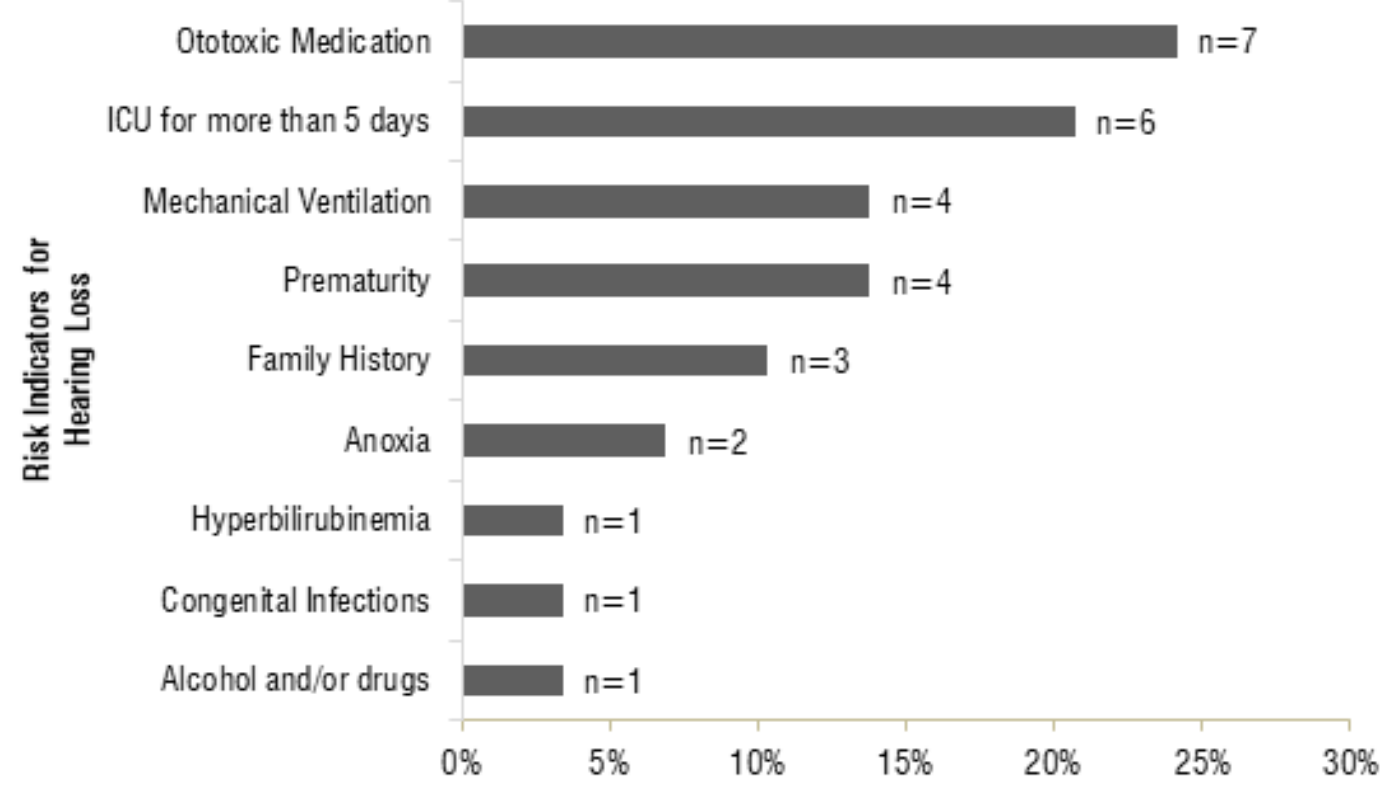

Key: ICU: Intensive Care Unit; \%: Percentage

Figure 2. Occurrence of risk indicators for hearing loss in the total of newborns/infants who didn't attend retest $(n=29)$

\section{DISCUSSION}

Data collected between 2015 and 2018 enabled the estimating of an evasion rate which was below those indicated in national and international guidelines ${ }^{9,10}$ for the NHS retest stage. Hence, this study observed an expressive abandon rate in this stage. This data's relevance is all the more emphasized in face of the impacts of not-diagnosed HL on the newborn's/infant's development. In addition, it was made evident that there had been no influence of the presence of RIHL in the retest evasion rate. The use of ototoxic medication was pointed out as the indicator of highest occurrence in those who didn't attend the retest.

International recommendations indicate that, in order to assure effectiveness of the NHS program, it's necessary that reassessment be performed in at least $90 \%$ of newborns that failed in screening ${ }^{10}$. In this study, the program reached the rate of $84.8 \%$ of coverage of these newborns, as the evasion rate of retesting was of $15.2 \%$ (Figure 1). The retest evasion rate in this research present a rate similar to that found in another study, which also obtained $15.2 \%$ of evasion in such stage ${ }^{16}$. Furthermore, additional researches present high retest evasion rates, reaching $24 \%{ }^{17}$, and even $29 \%{ }^{18}$. Such rates are worrisome, once they show an interruption in the program's continuity, as well as in the audiological follow-up of newborns with RIHL.

These data reflect the difficulty lived by national services to meet such effectiveness measures. Social inequalities may represent factors that hinder carrying out newborn screening tests in accordance with the assigned recommendations. A study has observed that such tests are more frequently performed in newborns of white ethnicity, in which cases those responsible for them have health insurance from private institutions, also having higher income. In addition to that, 
better results are expected for the South and Southeast regions of Brazil, when compared to its North and Northeast regions ${ }^{19}$. Attention should be called to the fact that all places previously mentioned are public maternity hospitals of different states in the South and Southeast regions of Brazil.

In spite of the relatives' adherence rate concerning the continuation of the NHS program's stages being essential for achieving satisfactory results throughout the child's development ${ }^{20}$, the performance of NHS still presents a low screening coverage, when compared to the other newborn screening tests. A study carried out in Southern Brazil revealed that $96.5 \%$ of the analyzed population had been submitted to the heel prick test, whereas only $65.8 \%$ stated having performed $\mathrm{NHS}^{19}$.

Even though the universality of NHS has been foreseen by law for years ${ }^{9,10}$, the national services' difficulty in assuring the effectiveness of this quality indicator is notorious ${ }^{11}$.

Several studies aimed at identifying the possible causes that might justify the non-attendance at the program's consecutive stages. Among these, the most frequent were: forgetfulness, unawareness of having an appointment scheduled ${ }^{21}$, lack of public transportation, being at work at the time of the scheduled appointment ${ }^{22}$, lack of interest, difficulty in reconciling the appointment with family routine ${ }^{12}$, low attendance at prenatal care, having more than one child, and the lack of a partner ${ }^{23}$.

In such context, this study sought to analyze the influence of the RIHL in the retest evasion rate of the $\mathrm{NHS}$ program. There was no association between the retest evasion rate and the presence of RIHL (Table 1). These results indicate that there being any risk indicators in the newborn's medical history doesn't cause greater concern in the family regarding possible $\mathrm{HL}$ and its consequences to the child's development. Furthermore, these results suggest that, even with a signed Statement of Responsibility, those responsible for the newborn don't attend the evaluation.

This study pioneered in the analysis of the variable $\mathrm{RIHL}$ and their influence on the retest evasion rate, for literature traditionally approaches the RIHL in its relation to the screening results. However, in order to assure the quality and efficacy of the NHS program, the analysis of this variable is made necessary, aiming at obtaining information as to how such variables may affect the other stages of the program.

It is inferred that the obtained result occur due to the newborn's/infant's family's unawareness of the NHS programs, as well as of the impact the RIHL may have on the individual's future auditory health ${ }^{22}$.

Brazilian studies show high rates of unawareness on the part of the family regarding the importance of the $\mathrm{NHS}^{22,24,25}$. In one of them, $81.2 \%$ of the parents and/or adults responsible for the child reported having previous knowledge about neither the program nor any of the names and terms used in the field ${ }^{24}$. Along with that, another study presents similar rates, reporting that only $30 \%$ of pregnant women had received information related to the NHS during prenatal care. This information was mostly given by doctors, followed by speech-language-hearing pathologists ${ }^{25}$.

Hence, the importance of the multidisciplinary team is highlighted, particularly the doctor's role, as it is an important strategy for facilitating information to be spread regarding the importance of the program and of early diagnosis of $\mathrm{HL}$, once the information given by pediatricians is known to be influential ${ }^{23}$. Medical referral to the NHS may be emphasized as a contributing factor to retest attendance. Yet, literature refers to the lack of adequate knowledge on the part of these professionals concerning early $\mathrm{HL}$ diagnosis ${ }^{26}$, revealing the need of better communication between medical staff and speech-language-hearing pathologists. Furthermore, attention should be called to the importance and necessity of speech-language-hearing pathologists integrating, along with the other professionals, the team responsible for prenatal care in the national health institutions, since they are the professional apt to bring awareness and guidance to the population regarding aspects related to $\mathrm{HL}^{3}$.

The absence of an integrated discourse involving the teams in the maternity hospitals is characteristic of a fragmented health system. For this reason, the speechlanguage-hearing pathologists and the multidisciplinary team are the ones who should do the job of guiding the pregnant women, beginning at prenatal care, regarding possible alterations experienced in the neonatal stage, especially concerning the $\mathrm{RIHL}^{27}$.

As for the occurrence of RIHL in the cases of retest evasion, the most frequently registered indicator was the use of ototoxic medication, followed by stay in ICU for more than five days and mechanical ventilation (Figure 2). Additional researches suggest that such indicators have greater occurrence due to perinatal complications being commonly observed in maternity hospitals ${ }^{28,29}$. However, an important aspect to be considered is that indicators may vary according to the characteristics of each service. For instance, reference 
care services for high-risk pregnancies possibly have an ICU; therefore, staying there for more than five days along with the use of ototoxic medication will be an occurring indicator. Such is the case of the maternity hospital in question.

Because of unawareness on the part of pregnant women, nursing mothers and relatives regarding the importance of the NHS, the child auditory health programs must develop collective health measures aiming at contributing to the training of the professionals working with basic health care. Moreover, the NHS programs should be further integrated to the public health functions. An interesting measure would be the development of new guidance protocols, which may be implemented in primary health care, during prenatal care, with the purpose of making the population sensitive to and conscious of this issue, especially by informing about the RIHL.

\section{CONCLUSION}

The retest evasion rate verified in this study is below that indicated by national and international guidelines (JCIH and COMUSA - Portuguese acronym for multiprofessional committee on auditory health), reaching $15.2 \%$. It has been verified that the presence of RIHL didn't influence the retest evasion rate. In addition, the use of ototoxic medication, followed by stay in ICU for more than five days, were the most frequent RIHL in the sample group of newborns/infants that didn't attend at the retest stage.

\section{REFERENCES}

1. Yoshinaga-itano C, Sedey AL, Coulter DK, Mehl AL. Language of early-and later-identified children with hearing loss. Pediatrics. 1998;102(5):1161-71.

2. Pimperton $H$, Blythe $H$, Kreppner $J$, Mahon $M$, Peacock JL, Stevenson $\mathrm{J}$ et al. The impact of universal newborn hearing screening on long-term literacy outcomes: a prospective cohort study. Arch Dis Child. 2016;101(1):9-15.

3. Brasil. Ministério da Saúde (MS). Diretrizes de Atenção da Triagem Auditiva Neonatal. 2012. [acessado 2018 Dez 19]. Disponível em: http:// bvsms.saude.gov.br/bvs/publicacoes/diretrizes_ atencao_triagem_auditiva_neonatal.pdf.

4. Geneva. World Health Organization. Global estimates on hearing loss. World Health Organization. 2018. [acessado 2018 Dez 19].
Available in: http://www.who.int/pbd/deafness/ estimates/en/.

5. Chadha S, Ciezaa A, Reyes K. Public health approach to hearing across the life course: a call-for papers. Bull World Health Organ. 2018;96(5):592.

6. Lewis DR. Evidências para a realização da Triagem Auditiva Neonatal Universal. In: Bevilacqua MC, Martinez MAN, Balen AS, Pupo AC, Reis ACM, Frota $S$ (orgs). Tratado de Audiologia São Paulo: Ed. Santos; 2011. p.495-513.

7. Yoshinaga-Itano C. Levels of evidence: universal newborn hearing screening (UNHS) and early hearing detection and intervention systems (EHDI). J Commun Disord. 2004;37(5):451-65.

8. Farhat A, Ghasemi MM, Akhondian J, Mohammadzadeh A, Esmaeili $\mathrm{H}$, Amiri $\mathrm{R}$ et al. Comparative study of hearing impairment among healthy and intensive care unit neonates in Mashhad, North East Iran. Iran J Otorhinolaryngol. 2015;27(4):273-7.

9. Lewis DR, Marone SAM, Mendes BCA, Cruz OLM, Nóbrega M. Multiprofessional committee on auditory health: COMUSA. Braz J Otorhinolaryngol. 2010;76(1):121-8.

10. Joint Committee on Infant Hearing. American Academy of Pediatrics. Year 2007 position statement: principles and guidelines for early hearing detection and intervention programs. Pediatrics. 2007;120(4):898-921.

11. Cavalcanti HG, Melo LPF, Buarque LFSFP, Guerra RO. Overview of newborn hearing screening programs in Brazilian maternity hospitals. Braz $\mathrm{J}$ Otorhinolaryngol. 2014;80(4):346-53.

12. Alvarenga KF, Gradet JM, Araújo ES, Bevilacqua MC. Newborn hearing screening: reasons for the evasion of families in the process of early detection. Rev Soc Bras Fonoaudiol. 2012;17(3):241-7.

13. Berni PS, Almeida EO, Amado BC, Almeida Filho N. Universal neonatal screening: index of retest effectiveness among newborns of a public hospital in Campinas - Brazil. Rev. CEFAC. 2010;12(1):122-7.

14. Pasha YZ, Zamani M, Fard AH, Pasha EZ. Screening of hearing in newborn infants: follow-up and outcome after 40930 births in Babol, Northern Iran. Arch Iran Med. 2018;21(9):382-6.

15. Bertuol B, Melo A, Corrêa BM, Biaggio EPV. Taxa de evasão no reteste da triagem auditiva neonatal: a relevância do Termo de Responsabilidade. Saúde. 2016;42(2):129-35. 
16. Lima PT, Goldbach GM, Monteiro CM, Ribeiro MG. A triagem auditiva neonatal na Rede Municipal do Rio de Janeiro, Brasil. Cien Saude Colet. 2015;20(1):57-63.

17. Faistauer M, Augusto TAM, Floriano M, Tabajara CC, Martini CM, Schmidt VB et al. Implementação do programa de triagem auditiva neonatal universal em hospital universitário de município da região Sul do Brasil: resultados preliminares. Rev AMRIGS. 2012;56(1):22-5.

18. Januário GC, Lemos SMA, de Lima Friche AA, Alves CR. Quality indicators in a newborn hearing screening service. Braz J Otorhinolaryngol. 2015;81(3):255-63.

19. Mallmann MB, Tomasi YT, Boing AF. Neonatal screening teste in Brazil: prevalence rates and regional and socioeconomic inequalities. J Pediatr. 2019;S0021-7557(18):30816-7.

20. Alvarenga KF, Belavilacqua MC, Melo TM, Lopes AC, Moret ALM. Families participation in Hearing Health Programs: a descriptive study. Rev Soc Bras Fonoaudiol. 2011;16(1):49-53.

21. Kanji A, Krabbenhof K. Audiological follow-up in a risk-based newborn hearing screening programme: An exploratory study of the influencing factors. S Afr J Commun Disord. 2018;65(1):587-93.

22. Luz I, Ribas A, Kozlowski L, Willig M, Berberian AP. Newborn hearing screening in a public maternity ward in Curitiba, Brazil: determining factors for not retesting. Int Arch Otorhinolaryngol. 2016;20(4):300-4.
23. Fernandes JC, Nozawa MR. Effectiveness study of the universal newborn hearing screening. Cien Saude Colet. 2010;15(2):353-61.

24. Freitas TVD, Lewis DR, de Nóbrega GB. Processo de triagem auditiva neonatal e o impacto dos resultados. Distúrb. Comum. 2014;26(4):725-33.

25. Sabbag JC, Lacerda ABM. Neonatal Hearing Screening in primary health care and family health care. CoDAS. 2017;29(4):e20160102.

26. Campos AC, Shirane HY, Takemoto PV, Lourenço EA. Universal newborn hearing screening: knowledge of pediatricians and neonatologists in the city of Jundiaí, São Paulo, Brazil. Braz J Otorhinolaryngol. 2014;80(5):379-85.

27. Todd NW. Universal newborn hearing screening follow-up in two Georgia populations: newborn, mother and system correlates. Int $\mathrm{J}$ Pediatr Otorhinolaryngol. 2006;70(5):807-15.

28. Wroblewska-Seniuk K, Greczka G, Dabrowski P, Szyfter-Harris J, Mazela J. Hearing impairment in premature newborns - Analysis based on the national hearing screening database in Poland. PLoS One. 2017:14;12(9):e0184359.

29. Oliveira CS, Daiane B, Santiago DB, Valente JSP, Borja ALVF, Bernardi APA. Prevalence of risk indices for hearing loss in 'failure' results of newborn hearing screening. Rev. CEFAC. 2015;17(3):827-35. 